\title{
Overall elemental dry deposition velocities measured around Lake Michigan
}

\author{
Seung-Muk Yi ${ }^{\mathrm{a}}$, Usama Shahin ${ }^{\mathrm{b}}$, Jakkris Sivadechathep ${ }^{\mathrm{c}}$, \\ Sait C. Sofuoglu ${ }^{\mathrm{c}}$, Thomas M. Holsen ${ }^{\mathrm{b}, *}$ \\ a Department of Environmental Science and Engineering, Ewha Women's University, 11-1, Daehyon, Seodaemun, Seoul 120-750, South Korea \\ ${ }^{\mathrm{b}}$ Department of Civil and Environmental Engineering, Clarkson University, Box 5710, Potsdam, NY 13699, USA \\ ${ }^{\mathrm{c}}$ Department of Chemical and Environmental Engineering, Illinois Institute of Technology, IIT Center, Chicago, IL 60616, USA
}

Received 15 October 1999; accepted 12 April 2000

\begin{abstract}
Overall dry deposition velocities of several elements were determined by dividing measured fluxes by measured airborne concentrations in different particle size ranges. The dry deposition measurements were made with a smooth surrogate surface on an automated dry deposition sampler (Eagle II) and the ambient particle concentrations were measured with a dichotomous sampler. These long-term measurements were made in Chicago, IL, South Haven, MI, and Sleeping Bear Dunes, MI, from December 1993 through October 1995 as part of the Lake Michigan Mass Balance Study. In general, the dry deposition fluxes of elements were highly correlated with coarse particle concentrations, slightly less well correlated with total particle concentrations, and least well correlated with fine particle concentrations. The calculated overall dry deposition velocities obtained using coarse particle concentrations varied from approximately $12 \mathrm{~cm} \mathrm{~s}^{-1}$ for $\mathrm{Mg}$ in Chicago to $0.2 \mathrm{~cm} \mathrm{~s}^{-1}$ for some primarily anthropogenic metals at the more remote sites. The velocities calculated using total particle concentrations were slightly lower. The crustal elements $(\mathrm{Mg}, \mathrm{Al}$, and $\mathrm{Mn})$ had higher deposition velocities than anthropogenic elements ( $\mathrm{V}, \mathrm{Cr}, \mathrm{Cu}, \mathrm{Zn}, \mathrm{Mo}, \mathrm{Ba}$ and $\mathrm{Pb}$ ). For crustal elements, overall dry deposition velocities were higher in Chicago than at the other sites. (C) 2001 Elsevier Science Ltd. All rights reserved.
\end{abstract}

Keywords: Dry deposition velocity; Flux; Aerosol concentration; Elemental composition; Surrogate surface

\section{Introduction}

Dry deposition of atmospheric contaminants is known to be an important removal mechanism of trace metals. Despite its importance, the understanding of dry deposition to natural surfaces is far from complete (Davidson, 1990). Recent advances have been made by using a surrogate surface to directly measure dry deposition. This technique can be used to directly assess deposited material and allows comparisons to be made between measured and modeled data (Holsen and Noll, 1992; Davidson et al., 1985).

\footnotetext{
*Corresponding author. Tel.: + 1-315-268-3851; fax: + 1315-268-7985.

E-mail address: holsen@clarkson.edu (T.M. Holsen).
}

Recent studies have shown that surrogate surfaces can be used: (1) over extended periods of time and at different locations to provide information on temporal and spatial variations in dry deposition of a species, (2) to estimate lower limits to aerosol dry deposition to rougher, natural surfaces if they are smooth horizontal collectors that do not appreciably disturb airflow and (3) as research instruments for investigating the influence of surface geometry, atmospheric properties, and characteristics of the depositing species on dry deposition (Davidson et al., 1985). Measurements made with a smooth surrogate surface with a sharp leading edge have been shown to agree well with results of modeled dry deposition if complete atmospheric size distributions are used (Holsen and Noll, 1992; Paode et al., 1998; Sofuoglu et al., 1998).

A variety of models have been developed to predict deposition velocities. For example, Slinn and Slinn (1980, 
1981) developed a model for particles deposited on a water surface that describes delivery from the free atmosphere by eddy diffusion and sedimentation, followed by transport across the viscous sublayer by Brownian diffusion, inertial impaction, and sedimentation. Williams (1982) developed a similar model that includes separate expressions for smooth and rough areas of the water surface. Both of these models assumed the water is a perfect sink. Fairall and Larsen (1984) added the effects of a non-perfect sink surface by including a surface resistance term.

Since these types of models are complex and require information that is often difficult to obtain, dry deposition is often estimated using total or partially size segregated particle concentrations and average or overall deposition velocities. These deposition velocities are difficult to predict because they vary with atmospheric conditions, location and the size distribution of the depositing species. It is common to have one order of magnitude variations in calculated overall deposition velocities due to the differences in methods used to establish the associated particle size distribution (Van Aalst, 1988). The number of steps used to discretize the particle's size range has a large influence on the computed dry deposition velocity (Dulac et al., 1989) due to the non-linear dependence of the calculated deposition velocity on particle diameter and shape of the size distribution curve. For these reasons, the use of an overall deposition velocity, in combination with measured ambient concentrations, to estimate dry deposition, often greatly underestimates the contribution of coarse particles, particularly those $>10 \mu \mathrm{m}$, to dry deposition (Holsen et al., 1991; Holsen and Noll, 1992). As a consequence, many estimates of dry deposition made using this technique are probably underestimated.

The objectives of this research were (1) to measure long-term elemental dry deposition and ambient concentration at various locations around Lake Michigan; and (2) to determine overall dry deposition velocities for several elements at various locations around the lake.

\section{Experimental section}

\subsection{Sampling program}

Samples were collected at three locations around Lake Michigan as part of the Lake Michigan Mass Balance (LMMB) Project: Sleeping Bear Dunes, MI (SBD), near South Haven, MI (SH), and at Illinois Institute of Technology in Chicago (IIT). Details about these locations are presented elsewhere (Paode et al., 1998; Sofuoglu et al., 1998; Franz et al., 1998). The dry deposition samples were collected with Eagle II automatic dry deposition collectors. This sampler contains two deposition plates mounted on arms that are pointed into the wind with a wind vane. These plates are automatically covered when a moisture sensor detects rain or snow and exposed to the atmosphere during dry periods. The sampler is described in more detail elsewhere (Franz et al., 1998; Sofuoglu, 1996).

The dry deposition samples were collected on carefully cleaned Mylar strips covered with Apezion L grease. Details of sample preparation are described in Paode et al. (1998) and the Illinois Institute of Technology, Air Quality Laboratory SOP (US EPA, 1996). Sampling started on December 1993 and concluded in October 1995. Sampling times extended between 4 and 57 days depending on the sampling site and season with an average of 22 days (Franz et al., 1998; Shahin et al., 2000).

Ambient particle concentrations were measured using commercial dichotomous samplers (Andersen Samplers, Atlanta, GA) operated by the Illinois Water Survey. This sampler collects fine (aerodynamic diameter $<2.5 \mu \mathrm{m}$ ) and coarse (aerodynamic diameter $>2.5 \mu \mathrm{m}$ ) airborne particles on separate $37-\mathrm{mm}, 0.2 \mu \mathrm{m}$ average pore size Teflon filters at a rate of $1 \mathrm{~m}^{3} \mathrm{~h}^{-1}$ (Gelman, Ann Arbor, $\mathrm{MI})$. The dichotomous sampler is normally equipped with an inlet that excludes particles larger than $10 \mu \mathrm{m}$. This inlet was removed and the sampler was mounted in a standard high-volume sampler shelter so that larger particles could be collected. It is unknown how removing the inlet increased measured coarse particle concentrations; however, the increase is likely to be small because these types of samplers have been shown to have poor collection efficiencies for large coarse particles (Hofschreuder et al., 1983; Chow, 1995). Quarterly calibrations were performed using a mass flow meter. The sampler operated for four 24-h periods within each 4-week sampling cycle to collect about $100 \mathrm{~m}^{3}$ of air. The filters were handled at a clean bench in the laboratory.

\subsection{Analysis}

Analytical methods are described in detail elsewhere (Paode et al., 1998; Sofuoglu et al., 1998). Briefly, the grease and associated particles from the deposition strips were washed into Teflon containers and digested with an ultra-pure nitric acid solution in a microwave oven in a Class 100 Clean Room at the University of Michigan Air Quality Laboratories. Samples were subsequently analyzed with a Perkin-Elmer 6000 inductively coupled plasma-mass spectrometer (ICP-MS).

Metals in airborne particles collected by the dichotomous sampler were measured by X-ray fluorescence spectrometry (XRF) at the U.S. EPA's Atmospheric Research and Exposure Assessment Laboratory. The analyzer is an energy dispersive spectrometer, custom made by Lawrence Berkeley Laboratory. The standard operating procedures have been previous published (Kellogg, 1992). Commercial standards consisting of thin 
Table 1

Average long-term dry deposition flux for elements in three sampling sites

\begin{tabular}{|c|c|c|c|c|c|c|}
\hline \multirow[t]{2}{*}{ Species } & \multicolumn{2}{|l|}{ Chicago } & \multicolumn{2}{|l|}{ South Haven } & \multicolumn{2}{|c|}{ Sleeping Bear Dunes } \\
\hline & $\begin{array}{l}\text { Ave. flux } \\
\left(\mathrm{mg} \mathrm{m}^{-2} \mathrm{day}^{-1}\right)\end{array}$ & SD & $\begin{array}{l}\text { Ave. flux } \\
\left(\mathrm{mg} \mathrm{m}^{-2} \mathrm{day}^{-1}\right)\end{array}$ & SD & $\begin{array}{l}\text { Ave. flux } \\
\left(\mathrm{mg} \mathrm{m}^{-2} \mathrm{day}^{-1}\right)\end{array}$ & SD \\
\hline $\mathrm{Mg}$ & 2.27 & 1.25 & 0.52 & 1.8 & 0.058 & 0.028 \\
\hline $\mathrm{Al}$ & 1.04 & 1.05 & 0.34 & 0.65 & 0.074 & 0.060 \\
\hline V & 0.0033 & 0.0033 & 0.0012 & 0.0031 & 0.00017 & 0.000314 \\
\hline $\mathrm{Cr}$ & 0.0057 & 0.0056 & 0.00074 & 0.00084 & 0.0016 & 0.0038 \\
\hline $\mathrm{Mn}$ & 0.058 & 0.057 & 0.021 & 0.046 & 0.0035 & 0.0026 \\
\hline $\mathrm{Cu}$ & 0.063 & 0.050 & 0.031 & 0.035 & 0.079 & 0.17 \\
\hline $\mathrm{Zn}$ & 0.12 & 0.11 & 0.051 & 0.046 & 0.068 & 0.082 \\
\hline Mo & 0.00096 & 0.00078 & 0.00015 & 0.00025 & 0.00049 & 0.0012 \\
\hline $\mathrm{Ba}$ & 0.028 & 0.022 & 0.0094 & 0.027 & 0.0023 & 0.0019 \\
\hline $\mathrm{Pb}$ & 0.038 & 0.034 & 0.023 & 0.059 & 0.035 & 0.076 \\
\hline
\end{tabular}

film deposits on Nucleopore or standard polymer films are less than $0.1 \mathrm{ng} \mathrm{m}^{-3}$. Blank values for all elements were generally below the detection limits.

\subsection{Quality assurance/quality control}

The strict quality assurance and quality control guidelines developed for analysis of dry deposition samples as part of the LMMB were followed and are described in Paode et al. (1998) and Sofuoglu et al. (1998). These included development of method detection limits (MDLs), analysis of process and field blanks, and measurement of extraction efficiencies using Urban Particulate Matter (NIST 1643). Field blanks were occasionally slightly higher $(<0.2 \mathrm{ppb})$ than MDLs although they were 10-50 times lower than average metal concentrations in the samples. Recovery efficiencies for lead, copper and zinc ranged from 90 to $100 \%$ and were $60 \%$ for aluminum. The relative standard deviations were $<15 \%$ for both split and replicate samples.

\section{Results and discussion}

\subsection{Dry deposition flux}

Long-term dry deposition was measured at three sampling sites, Chicago, IL, South Haven, MI and Sleeping Bear Dunes, MI. Table 1 shows the average dry deposition flux for ten elements at these three sites (Shahin et al., 2000). The flux of primarily crustal elements was higher and more variable than the flux of primarily anthropogenic elements at all the sites. In addition, fluxes of all elements in Chicago were substantially higher and more variable than at the other sites. The average crustal elemental flux in Chicago was about 4-10 times higher than at South Haven and 10-20 times higher than at Sleeping Bear Dunes. The average fluxes of primarily anthropogenic elements in Chicago were approximately 3 times higher than at the other two sites. Results similar to those reported here were obtained for polychlorinated biphenyls and polycyclic aromatic hydrocarbons during the same study (Franz et al., 1998). Chicago fluxes of PCBs were on average 3 times higher than the non-urban PCBs fluxes. For PAHs the mean dry deposition flux ranged from $18 \mu \mathrm{g} \mathrm{m}^{-2}$ day $^{-1}$ in Chicago to $0.2 \mu \mathrm{g} \mathrm{m}^{-2}$ day $^{-1}$ in the South Haven. The PAH deposition rate in the near-shore region of southern Lake Michigan was $0.7 \mu \mathrm{g} \mathrm{m}^{-2} \mathrm{day}^{-1}$.

\subsection{Ambient concentration}

The average concentrations of primarily crustal elements were higher than those of primarily anthropogenic elements at all the sites (Table 2). The average concentration of $\mathrm{Zn}, \mathrm{Cu}$ and $\mathrm{Pb}$ were higher than the other anthropogenic elements at all three sites. In general, primarily crustal elements were found in the coarse particle size range and primarily anthropogenic elements were found in the fine particle size range 'however' there were several exceptions. The average copper concentration for coarse particles was higher than fine particles in Chicago (10.0 vs. $8.7 \mathrm{ng} \mathrm{m}^{-3}$ ) but lower at South Haven and Sleeping Bear Dunes (3.3 vs. 4.0 and 3.1 vs. $5.2 \mathrm{ng} \mathrm{m}^{-3}$, respectively). In South Haven, the V, Cr, and Mo concentrations were very evenly distributed between coarse and fine particles ( 0.5 vs. $0.4,0.2$ vs. 0.2 , and 0.1 vs. $0.3 \mathrm{ng} \mathrm{m}^{-3}$, respectively). Overall the concentrations of coarse particles were higher than fine particles for five anthropogenic elements $(\mathrm{V}, \mathrm{Cr}, \mathrm{Cu}, \mathrm{Mo}$, and $\mathrm{Ba})$ in Chicago, one element (V) in South Haven, and three elements (V, Cr, and Ba) in Sleeping Bear Dunes. In general, calculated standard deviations of all of the 


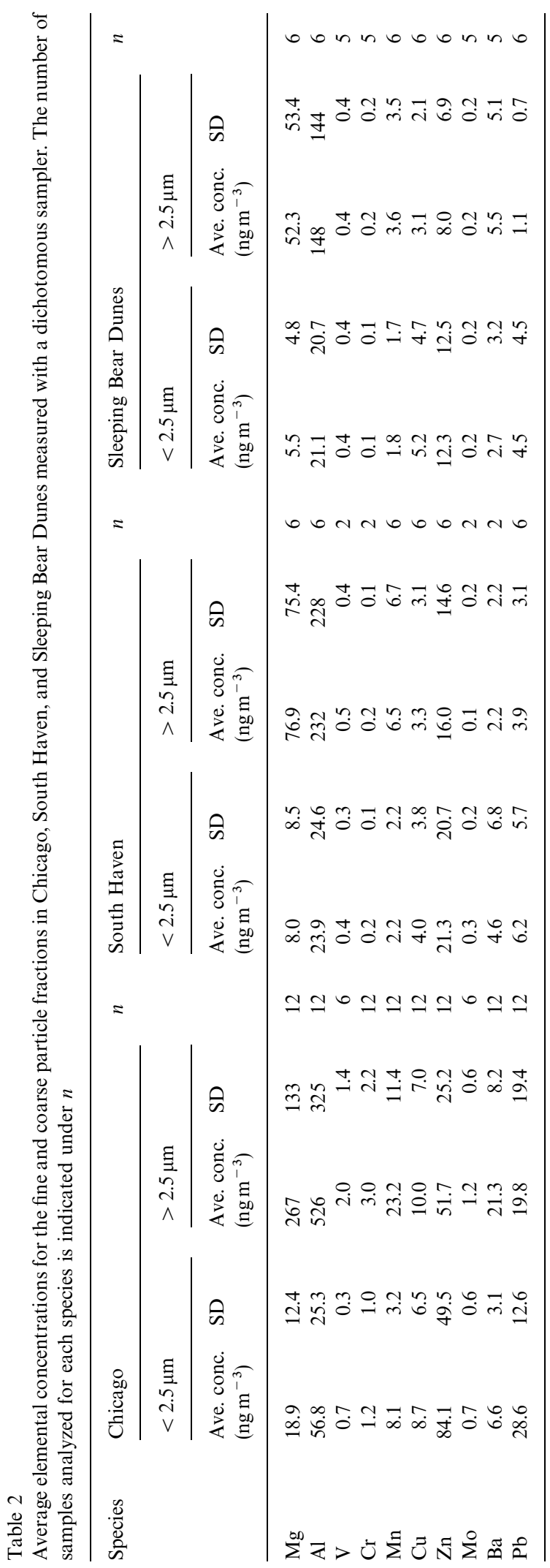

elements were similar in magnitude to average concentrations indicating that concentrations were highly variable.

\subsection{Overall dry deposition velocities}

\subsubsection{Results}

Best-fit overall dry deposition velocities were obtained by calculating the slope of the regression line between the measured dry deposition flux ( $y$-axis) and ambient concentration divided into several size categories ( $x$-axis). To increase sample sizes, the following elements were grouped together: $\mathrm{Mg}$; $\mathrm{Al}$ and $\mathrm{Mn} ; \mathrm{V}, \mathrm{Cr}, \mathrm{Mo}$, and $\mathrm{Ba}$; $\mathrm{Cu}$ and $\mathrm{Zn} ; \mathrm{Pb}$. This grouping was based on (1) preliminary analysis which found elements within each group had similar deposition velocities and (2) measured size distributions were found to be similar (Paode et al., 1998; Sofuoglu et al., 1998). Three different overall dry deposition velocities were determined for each element or groups of elements by using concentrations in three different particle size ranges (coarse, fine, and total). Fig. 1 is a graphical representation of the best-fit overall dry deposition velocities derived for South Haven. The overall best-fit overall dry deposition velocities for coarse, fine, and total particles for all of the elements for Chicago, South Haven, and Sleeping Bear Dunes are shown in Fig. 2. These overall deposition velocities vary depending on the concentrations of the elements in the various size ranges and are not associated with a particular particle size. For example, when a particular element has a smaller fine particle concentration than coarse particle concentration (as is common for crustal elements) the overall deposition velocity calculated using fine particle concentrations will be larger than that calculated using coarse particle concentrations.

The overall dry deposition velocities of crustal elements $(\mathrm{Mg} ; \mathrm{Al}$ and $\mathrm{Mn})$ obtained using coarse particle concentrations varied from 0.8 to $12.0 \mathrm{~cm} \mathrm{~s}^{-1}$ with correlation coefficients ranging from not statistically significant to 0.95 . The best-fit deposition velocities of anthropogenic elements $(\mathrm{V}, \mathrm{Cr}, \mathrm{Mo}$, and $\mathrm{Ba} ; \mathrm{Cu}$ and $\mathrm{Zn} ; \mathrm{Pb}$ ) obtained using coarse particle concentrations varied from 0.2 to $6.3 \mathrm{~cm} \mathrm{~s}^{-1}$ with correlation coefficients ranging from 0.45 to 0.99 .

The overall dry deposition velocities of the crustal elements obtained using fine particle concentrations were often not statistically significant. Those that were statistically significant were, in general, larger than those obtained using coarse particle concentrations $\left(5.5-22.8 \mathrm{~cm} \mathrm{~s}^{-1}\right)$ with smaller correlation coefficients $(0.59-0.86)$. The best-fit deposition velocities of anthropogenic elements obtained using fine particle concentrations were similar in magnitude to those in the coarse particle size range $\left(0.3-4.6 \mathrm{~cm} \mathrm{~s}^{-1}\right)$, however, the correlation coefficients were generally smaller (from not statistically significant to 0.90 ). 

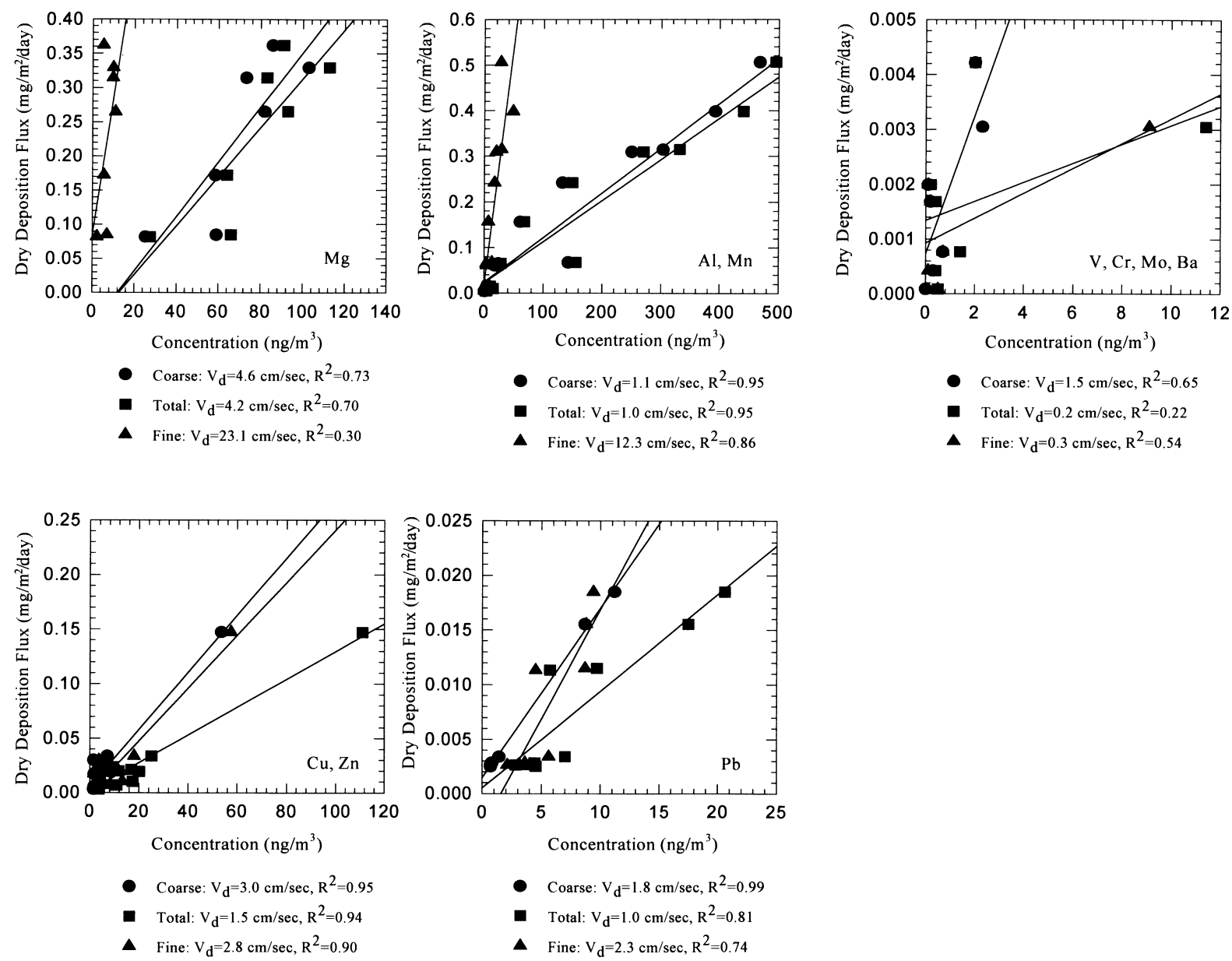

Fig. 1. Comparison between particle concentrations measured with a dichotomous sampler with the flux measured with a smooth surrogate surface in South Haven. The slope of the regression line is the best-fit overall dry deposition velocity.

The overall dry deposition velocities for crustal elements obtained using total particle concentrations (fine + coarse) were smaller than for those obtained using either the coarse or fine particle concentrations $\left(0.7-11.7 \mathrm{~cm} \mathrm{~s}^{-1}\right)$ with correlation coefficients ranging from not statistically significant to 0.95 . The best-fit deposition velocities of anthropogenic elements obtained using total particle concentrations were also smaller than those obtained using either the coarse or fine particle concentrations $\left(0.2-3.0 \mathrm{~cm} \mathrm{~s}^{-1}\right)$ with correlation coefficients ranging from not statistically significant to 0.94 .

The overall dry deposition velocities calculated for elements in Chicago, South Haven, and Sleeping Bear Dunes were compared with a paired $t$-test with a significance level of 0.05 . The only velocities that were found to be statistically different between sites were for crustal elements at Chicago and Sleeping Bear Dunes using both coarse and total particle concentrations. This is probably due to the higher concentration of large coarse particles at the urban site due to the higher level of human activities and presence of nearby industrial sources.

\subsubsection{Discussion}

For most of the elements the flux was very highly correlated with coarse particle concentrations. Occasionally, $r^{2}$ values were slightly higher between flux and total particle concentrations than for flux and coarse particle concentrations. For none of the elements were $r^{2}$ values highest using fine particle concentrations. This finding is because the majority of the flux is due to particles larger than $2.5 \mu \mathrm{m}$ in size due to their high deposition velocities (Davidson and Wu, 1990; Paode et al., 1998; Dulac et al., 1989; Holsen and Noll, 1992) and indicates that best approach to estimate overall dry deposition is by using either coarse or total particle concentrations. 

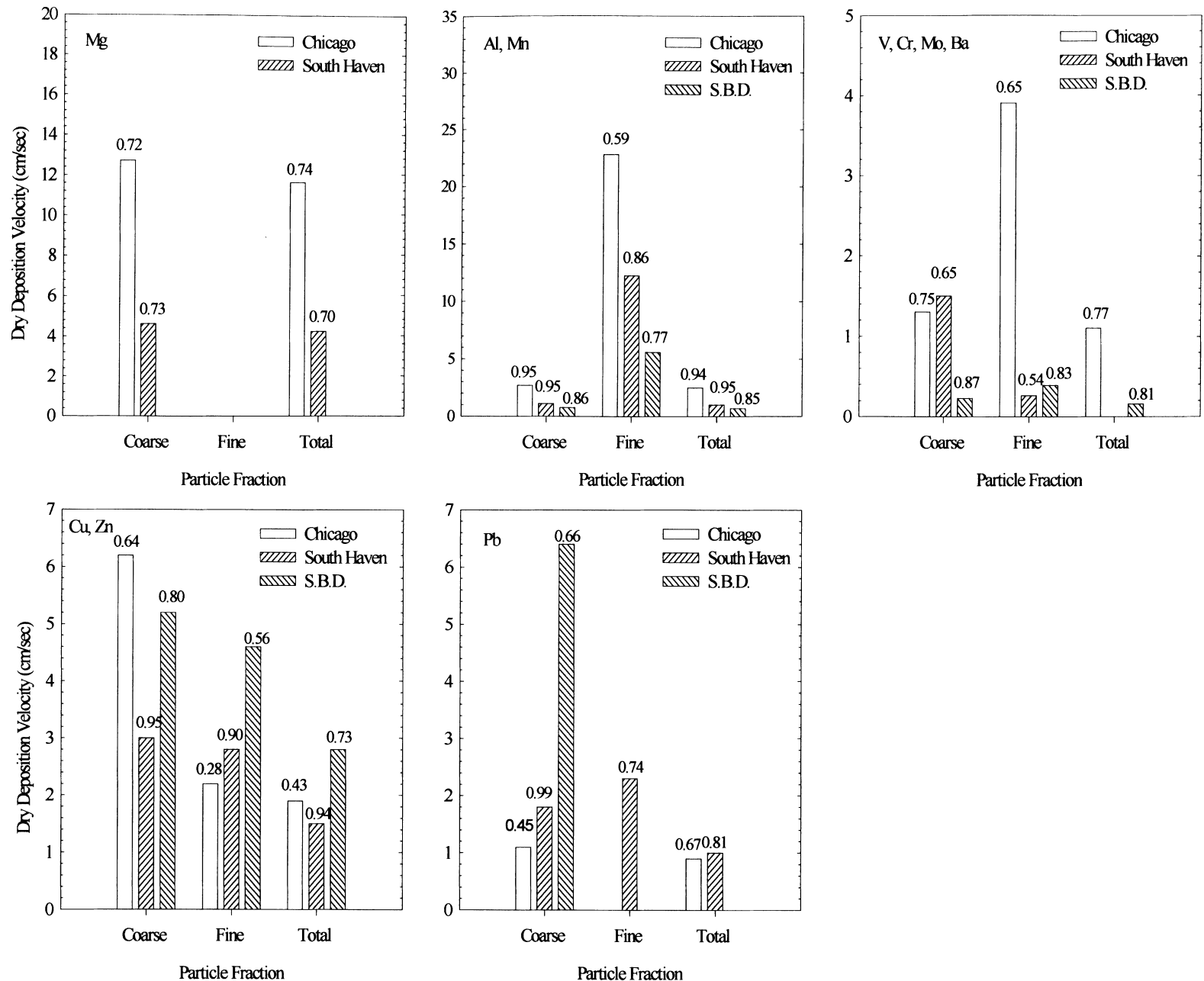

Fig. 2. Three overall dry deposition velocities calculated using the concentrations of three different size ranges of particles (coarse, fine, and total) and measured fluxes at three sampling sites (Chicago, South Haven, and Sleeping Bear Dunes). The number shown above the bar is the $r^{2}$ value for the regression lines between ambient concentration and flux. Missing bars indicate the regression was not statistically significant.

Measured overall dry deposition velocities for $\mathrm{Mg}$ in Chicago obtained using either coarse or total concentration were approximately $12 \mathrm{~cm} \mathrm{~s}^{-1}$. For South Haven the deposition velocity for $\mathrm{Mg}$ was approximately half of this value. For $\mathrm{Al}$ and $\mathrm{Mn}$ the deposition velocity in Chicago was significantly smaller $\left(2.5 \mathrm{~cm} \mathrm{~s}^{-1}\right)$ and again the deposition velocity for South Haven and Sleeping Bear Dunes was about half of this value. The larger deposition velocities for $\mathrm{Mg}$ than for $\mathrm{Al}$ and $\mathrm{Mn}$ is probably due to the greater concentration of $\mathrm{Mg}$ in the very large coarse particle (Sofuoglu et al., 1998).

For primarily anthropogenic elements there were no statistical differences between sites, however, there is a general trend of slightly higher deposition velocities for Chicago than the other sites. Measured deposition velocities for $\mathrm{V}, \mathrm{Cr}$, Mo and $\mathrm{Ba}$ obtained using total concentrations were approximately $0.5 \mathrm{~cm} \mathrm{~s}^{-1}$. For $\mathrm{Cu}$ and $\mathrm{Zn}$ the deposition velocity was significantly larger (approximately $2.0 \mathrm{~cm} \mathrm{~s}^{-1}$ ) and for lead it was between these values (approximately $1.3 \mathrm{~cm} \mathrm{~s}^{-1}$ ). Using coarse particle concentrations only yields somewhat larger deposition velocities.

These values are within the range of values published in the literature but probably slightly larger than average values. They agree fairly well the values recently reported by Zufall et al. (1998) for the Lake Michigan region except for $\mathrm{Cu}$ and $\mathrm{Mg}$ in which the values reported here are significantly larger than their earlier values. The highest deposition velocity reported by Zufall et al. (1998) was for $\mathrm{Mn}$ (approx. $9 \mathrm{~cm} \mathrm{~s}^{-1}$ ) which is somewhat larger than 
the value reported here $\left(2.5 \mathrm{~cm} \mathrm{~s}^{-1}\right)$. Reported values for primarily anthropogenic elements are generally smaller than $1 \mathrm{~cm} \mathrm{~s}^{-1}$ whereas deposition velocities for crustal elements often exceed this value (Davidson and $\mathrm{Wu}$, 1990). The values obtained are significantly greater than the values typically used by researchers in conjunction with PM10 concentrations $\left(0.2 \mathrm{~cm} \mathrm{~s}^{-1}\right)$ to calculate dry deposition flux to the Great Lakes (Stranchan and Eisenreich, 1988; Eisenreich and Stranchan, 1992; Hoff et al., 1996).

The average overall dry deposition velocities in all particle size ranges for crustal elements were higher than for anthropogenic elements. This finding is because crustal elements are usually associated with coarse particles (which have large deposition velocities) while anthropogenic elements generally associated with fine particles (which have small deposition velocities). Several other investigators have also shown that primarily anthropogenic elements are associated with smaller particle sizes and generally have smaller deposition velocities than crustal elements (Davidson et al., 1985; Davidson and $\mathrm{Wu}, 1990)$.

The average overall dry deposition velocities obtained using coarse particle concentrations for primarily crustal elements were only slightly larger than the ones obtained using the total particle concentrations at all sampling sites. This result indicates that the primarily crustal elements are mostly associated with coarse particles (i.e. coarse and total concentrations were very similar). Very high deposition velocities and poor correlation coefficients for crustal elements obtained using fine particle concentrations were obtained because of the small concentration of crustal elements in the fine particle mode. The overall dry deposition velocities obtained using fine particle concentration for the primarily anthropogenic elements were better correlated with the flux.

\section{Acknowledgements}

The authors would like to thank Jeff Lu, John Kelly, Mary Barden and Tom Van Zoeren for helping in the field sampling, Gerald J. Keeler for overseeing metals analysis and Clyde W. Sweet for supplying the concentration data. This work was funded in part by the Great Lakes National Program Office of the USEPA, Angela Bandemehr Project Officer.

\section{References}

Chow, J.C., 1995. Measurement methods to determine compliance with ambient air quality standards for suspended particles. Air Waste Management Association 45, $320-362$
Davidson, C.I., Wu, Y., 1990. Deposition of Particles and Vapors. Acidic Precipitation: Sources, Deposition, and Canopy Interactions, Vol. 3. Springer, New York, pp. 152-170.

Davidson, C.I., Lindberg, S.E., Schmidt, J.A., Cartwright, L.G., Landis, L.R., 1985. Dry deposition of sulfate onto a surrogate surface. Journal of Geophysical Research 90, 2123-2130.

Dulac, F., Buat-Menard, P., Ezat, U., Melki, S., Bergametti, G., 1989. Atmospheric input of trace metals to the Western Mediterranean: uncertainties in modeling dry deposition from cascade impactor data. Tellus 41B, 362-378.

Eisenreich, S.J., Stranchan, W.M.J., 1992. Estimating atmospheric deposition of toxic substance to the Great Lakes - an update. Workshop Report, Canada Centre for Inland Waters, Burlington, Ontario.

Fairall, C.W., Larsen, S.E., 1984. Dry deposition, surface production and dynamics of aerosols in the marine boundary layer. Atmospheric Environment 18, 69-77.

Franz, T., Eisenreich, S., Holsen, T.M., 1998. Dry deposition of particulate polychlorinated biphenyls and polycyclic aromatic hydrocarbons to Lake Michigan. Environmental Science and Technology 32 (23), 3681-3688.

Hoff, R.M., Strachan, W.M.J., Sweet, C.W., Chan, C.H., Shackleton, M., Bidleman, T.F., Brice, K.A., Burniston, D.A., Cussion, S., Gatz, D.F., Harlin, K., Schroeder, W.H., 1996. Atmospheric deposition of toxic chemicals to the Great Lakes: a review of data through 1994. Atmospheric Environment 30, 3505-3527.

Hofschreuder, P., Vrins, E., van Boxel, J., 1983. Sampling efficiency of aerosol samplers for large wind-borne particles - a preliminary report. Journal of Aerosol Science 14 (1), 65-68.

Holsen, T.M., Noll, K.E., 1992. Dry deposition of atmospheric particles: application of current models to ambient data. Environmental Science and Technology 26, 1807-1814.

Holsen, T.M., Noll, K.E., Liu, S.P., Lee, W.J., 1991. Dry deposition of polychlorinated biphenyls in urban areas. Environmental Science and Technology 25, 1075-1081.

Kellogg, R.B., 1992. Standard operating procedure for the source apportionment research branch LBL energy dispersive X-ray fluorescence spectrometer. Contract Report 68-DO-0106, Atmospheric Research and assessment Laboratory, US Environmental Protection Agency, Research Triangle Park, NC.

Paode, R.D., Sofuoglu, S.C., Sivadechathep, J., Noll, K.E., Holsen, T.M., Keeler, G.J., 1998. Dry deposition fluxes and mass size distributions of $\mathrm{Pb}, \mathrm{Cu}$ and $\mathrm{Zn}$ measured over Southern Lake Michigan during AEOLOS. Environmental Science and Technology 32 (12), 1629-1635.

Shahin, U., Lu, J., Yi, S.M., Paode, R.D., Holsen, T.M., 2000. Long term elemental dry deposition fluxes measured around Lake Michigan with an automated dry deposition sampler Environmental Science and Technology 34 (10), 1887-1892.

Slinn, S.A., Slinn, W.G.N., 1980. Predictions of particle deposition on natural waters. Atmospheric Environment 14, 1013-1016.

Slinn, S.A., Slinn, W.G.N., 1981. In: Eisenreich, S.J. (Ed.), Modeling of Atmospheric Particulate Deposition to Natural Waters. Ann Arbor Science Publishers, Ann Arbor, MI, pp. 23. 
Sofuoglu, S.C., Paode, R.D., Sivadechathep, J., Noll, K.E., Holsen, T.M., Keeler, G.J., 1998. Dry deposition fluxes and mass size distributions of mass, $\mathrm{Al}$ and $\mathrm{Mg}$ measured over Southern Lake Michigan during AEOLOS. Aerosol Science and Technology 29 (4), 281-293.

Stranchan, W.M.J., Eisenreich, S.J., 1988. Mass balancing of toxic chemicals in the Great Lakes: the role of atmospheric deposition. International Joint Commission: Windsor, Ontario.

US EPA, 1996. Lake Michigan Mass Balance Study - LMMBS - Method Compendium, Vol. 1.
Van Aalst, R.M., 1988. Input from the atmosphere. In: Solomon, et al. (Ed.), Pollution of the North Sea: An Assessment. Springer, Berlin, pp. 275-283.

Williams, R.M., 1982. A model for the dry deposition of particles to natural water surfaces. Atmospheric Environment 16, 1933-1938.

Zufall, M.J., Davidson, C.I., Caffery, P.F., Ondov, J.M., 1998. Airborne concentrations and dry deposition fluxes of particulate species to surrogate surfaces deployed in Southern Lake Michigan. Environmental Science and Technology 32, 1623-1628. 